\title{
Meeting visual quality objectives with operational radial-strip partial cutting in coastal British Columbia: A post-harvest assessment
}

\author{
by Stephen Sheppard ${ }^{1}$, Paul Picard ${ }^{2}$ and Robert G. D'Eon ${ }^{3}$
}

The spectacular aesthetic quality of British Columbia's coastal forests has long been an issue for forest managers who must often meet government-imposed visual quality objectives. The result of such objectives within traditional clearcutting silvicultural systems has often been large reductions in otherwise allowable timber removals. In this document we present the results of a post-harvest analysis of an operational trial using radial-strip partial harvesting in a highly visually sensitive area of coastal British Columbia. The analysis confirmed that this innovative form of partial harvesting successfully met visual quality requirements, while concurrently permitting significantly more timber extraction, in an operationally feasible manner, than would have been available under a traditional clearcutting system. We attribute the visual success of this harvest method in a highly visually sensitive area primarily to: (1) the radial pattern of linear clearings where it is not possible to see more than a few cleared strips from any one vantage point; (2) the avoidance of a regular series of parallel geometric clearings; (3) the narrow clearing width, which maximises bare ground screening; (4) feathered edges, which avoided highly contrasting edges of the strips; and (5) green tree retention across age classes. Faller and management experience with this method is expected to result in higher productivity and lower costs in the future. This harvesting technique appears to present a viable alternative to clearcutting for forest managers working in visually sensitive areas. Future work should focus on understanding and determining impacts on other factors such as ecological values and silvicultural goals.

Key words: aesthetics, partial-cutting, simulation, VIA, visual impact assessment, VQO, visual quality objective

La qualité esthétique spectaculaire des forêts côtières de la Colombie-Britannique a longtemps été un enjeu pour les aménagistes forestiers qui doivent souvent respecter les objectifs de qualité visuelle imposés par le gouvernement. Le résultat de ces objectifs relativement aux régimes sylvicoles traditionnels de coupe à blanc a souvent été une forte réduction du volume de bois récolté de ce qui aurait été autrement permis. Dans ce document, nous présentons les résultats d'une analyse post-récolte d'un essai opérationnel réalisé au moyen de coupes partielles par bandes radiales dans une zone très sensible aux impacts visuels de la côte de Colombie-Britannique. L'analyse a confirmé que cette forme innovatrice de coupe partielle a répondu avec succès aux exigences de qualité visuelle, tout en permettant une extraction significativement plus importante de bois réalisée de façon acceptable en terme d'opération qu'il aurait été possible d'effectuer selon un régime traditionnel de coupe à blanc. Nous attribuons le succès visuel de cette méthode de récolte dans une zone très sensible en terme de qualité visuelle principalement : (1) au patron radial des coupes linéaires où il n'est pas possible de voir plus que quelques bandes coupées à partir de n'importe quel point d'observation; (2) à l'évitement d'une série régulière de coupes géométriques parallèles; (3) à la largeur étroite des coupes, ce qui maximise le camouflage du sol dénudé; (4) aux extrémités biseautées, ce qui évite d'avoir des extrémités de bandes très contrastantes; et (5) à la rétention d'arbres verts de différentes classes d'âge. L'expérience des abatteurs et des aménagistes avec cette méthode devrait entraîner une plus grande productivité et une réduction des coûts dans l'avenir. Cette technique de récolte semble actuellement être une alternative viable à la coupe à blanc pour les aménagistes forestiers qui travaillent dans des zones sensibles à la qualité visuelle. Les prochains travaux devraient porter sur la compréhension et l'identification des conséquences sur les autres facteurs comme les valeurs écologiques et les objectifs sylvicoles.

Mots-clés : esthétique, coupe partielle, simulation, ÉIV, évaluation de l’impact visuel, OQV, objectif de qualité visuelle

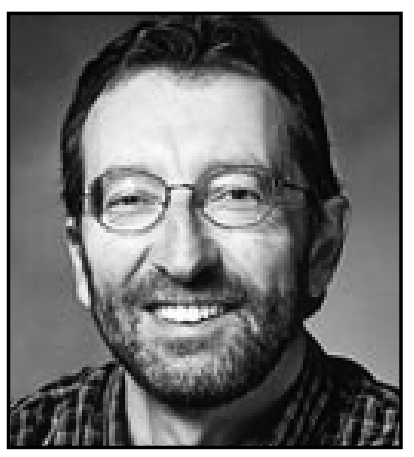

Stephen Sheppard

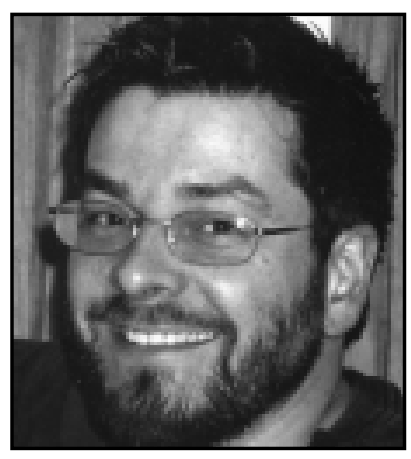

Paul Picard

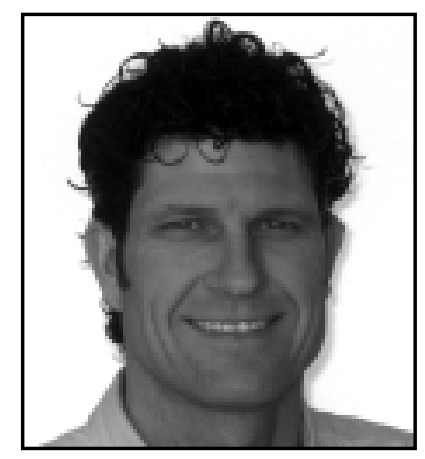

Robert G. D'Eon

${ }^{1}$ Collaborative for Advanced Landscape Planning (CALP), Department of Forest Resources Management and Landscape Architecture Program, 2424 Main Mall, University of British Columbia, Vancouver, British Columbia, V6T 1Z4. E-mail: shep@interchange.ubc.ca

${ }^{2}$ Collaborative for Advanced Landscape Planning (CALP), Department of Forest Resources Management, 2424 Main Mall, University of British Columbia, Vancouver, British Columbia, V6T 1Z4. E-mail: picard@interchange.ubc.ca

${ }^{3}$ RR1, S1, C21, Crescent Valley, BC, V0G 1H0. E-mail: rdeon@interchange.ubc.ca 


\section{Introduction}

The spectacular visual quality of British Columbia's (BC) coastal forest landscapes has been a cornerstone of its tourism industry and a key issue in provincial forest management for decades. In the context of the logging industry's heavy reliance on the practice of clearcutting despite a public dislike for this practice (Pâquet and Bélanger 1997, Robson et al. 2000, Picard 2002 and references therein), British Columbia currently implements restrictive visual quality requirements in areas of high visual concern (BC Ministry of Forests 2001). The ultimate result of such regulations under traditional clearcutting methods is large reductions in timber extraction in visually sensitive areas (Sheppard 2001). While this may meet multiple public demands, it is often viewed by the forest industry as a major constraint on timber volumes. Early modelling studies of the predicted visual effects of various harvesting techniques show, however, that maintaining visual quality is a major constraint only when clearcutting is considered the main course of action (BC Ministry of Forests 1996; Picard 2002; Picard and Sheppard 2002a, b). Are these predictions borne out in practice? Unfortunately, very few postharvesting evaluations of visual impacts have been documented in the scientific literature, and even fewer have looked at highretention ( $>50 \%$ retention) cable harvesting techniques, which are still relatively uncommon in British Columbia.

Our objective in this paper is to report a post-harvest case study in coastal $\mathrm{BC}$ where an innovative type of partial cutting was performed. This was an attempt to meet visual quality requirements, while concurrently permitting, in a profitable manner, significantly more timber extraction than would have been available under a traditional clearcutting system. Such studies are of particular interest and relevance to forest managers in publicly contentious and visually sensitive areas, and raise important questions on the impact of such partial cutting techniques on other values.

\section{Background and Study Area}

In 1994, Timfor Contractors Ltd. (hereafter referred to as Timfor), a logging operator with many years of logging experience on the BC coast, was advised that their harvesting operations around Knight Inlet were under threat of becoming suspended indefinitely, as a result of implementation of the newly formulated BC Forest Practices Code (FPC; Province of British Columbia 1996). The proximal cause of this threat was an almost total exclusion of available harvest areas due to perceived constraints imposed by the FPC on highly visible, steep slopes with restrictive visual quality requirements (BC Ministry of Forests 2001). To overcome this situation, the BC Ministry of Forests accepted bids for a forest license (FL A53812) using new and innovative approaches to harvest timber on the visually sensitive slopes of Knight Inlet (Johnson 1998, Siddall 2000). Upon review of five applications from Timfor and others, Timfor was awarded an experimental non-renewable license to harvest $175000 \mathrm{~m}^{3}$ of wood over a five-year period (1997-2002) from the Port McNeil Forest District within the Kingcome Timber Supply Area.

The study area in this case was located on the mid-coast of BC, on the north-facing slopes of Knight Inlet $\left(126^{\circ} 6^{\prime} \mathrm{W}\right.$, $50^{\circ} 38^{\prime} \mathrm{N}$; Fig. 1). Generally, the area can be described as a coastal old-growth forest mountain landscape with very steep and broken terrain (Fig. 2). The forests were within the Coastal
Western Hemlock biogeoclimatic zone described by Green and Klinka (1994), and in the NDT1 natural disturbance zone, characterised by rare stand-initiating events usually resulting in uneven-aged or multi-storied even-aged forests with mean disturbance return intervals around 250 years (BC Ministry of Forests 1995). Stands were predominantly mixes of old-growth ( $>250$ years) Western redcedar (Thuja plicata) and Western hemlock (Tsuga hetrophylla). However, merchantable timber was composed of $48 \%$ hemlock, $30 \%$ redcedar, 17\% Yellow cedar (Chamaecyparis nootkatensis), 4\% Red alder (Alnus rubra) and 1\% Douglas-fir (Pseudotsuga menziesii spp. Menziesii). Wood volumes of about $750 \mathrm{~m}^{3} / \mathrm{ha}$ and mean annual increments from $3.2 \mathrm{~m}^{3} / \mathrm{yr} / \mathrm{ha}$ to $9.0 \mathrm{~m}^{3} / \mathrm{yr} / \mathrm{ha}$ were typical. About $10-12 \%$ of the timber qualified as poles. The pre-harvest age class distributions were $38 \%$ over 250 years, $17 \%$ between 80 and 250 years, $33 \%$ between 40 and 80 years, and $12 \%$ below 40 years.

Slope gradients on target harvest areas were $\leq 60 \%$, but the general area included much steeper rock bluff terrain that presented stability concerns. Worker safety was also a large concern due in part to the presence of old-growth forests (which inherently contain hazards such as snags, root rot, and dead tops; Stathers et al. 1994) combined with steep terrain and slope stability issues. Slopes in the study area were highly visible and had low visual absorption capacity (i.e., uniform-appearing vegetation with few opportunities to blend new activities into existing landscape patterns). Due to its scenic nature and other environmental values, the area supported a thriving tourism industry (e.g., fly-in resorts, fishing, and other forms of outdoor recreation).

\section{Harvest Plan Design and Implementation}

Between 1998 and 2000, Timfor removed approximately 60\% of the basal area from target stands using a radial-strip harvesting method. Three blocks of 117 ha, 145 ha, and 66 ha gross area, respectively, were harvested, and yielded $33143 \mathrm{~m}^{3}$, $51390 \mathrm{~m}^{3}$, and 25818 net $^{3}$, respectively. The removal pattern consisted of 5-m corridors (finished width $=10 \mathrm{~m}$ ) oriented like the spokes of a wheel from a landing (Fig. 3). Leave strips between corridors, which were up to $70 \mathrm{~m}$ wide, were subsequently thinned (up to 50\% removals) and feathered, a selective removal technique used to soften the appearance of harvest block edges. Using a sky-line yarding system with lateral-yarding capability, $90 \%$ of yarding was uphill and ranged from 300 to $500 \mathrm{~m}$ yarding distance. Target trees were selected and manually felled by fallers - technique referred to as "faller-select." Prior to removals, fallers were provided with guidelines and information on retention objectives in order to guide tree selection. An attempt was made to produce a representative stand profile (i.e., trees were removed in proportion to stand composition by species).

Road construction was challenging due to very steep terrain and adverse grades (Johnson 1998). Particularly challenging was the placement of landings that required relatively flat ground. Despite these difficulties however, Timfor believed (E. Preus, personal communication) the final road length was less than what would have been required at this location under a traditional clearcutting scenario, contradicting conventional wisdom that more roads are required under a selective removal system. This appeared to result in this case, at least partially, from FPC adjacency constraints that require traditional clearcut-harvest blocks to maintain a minimum spacing 


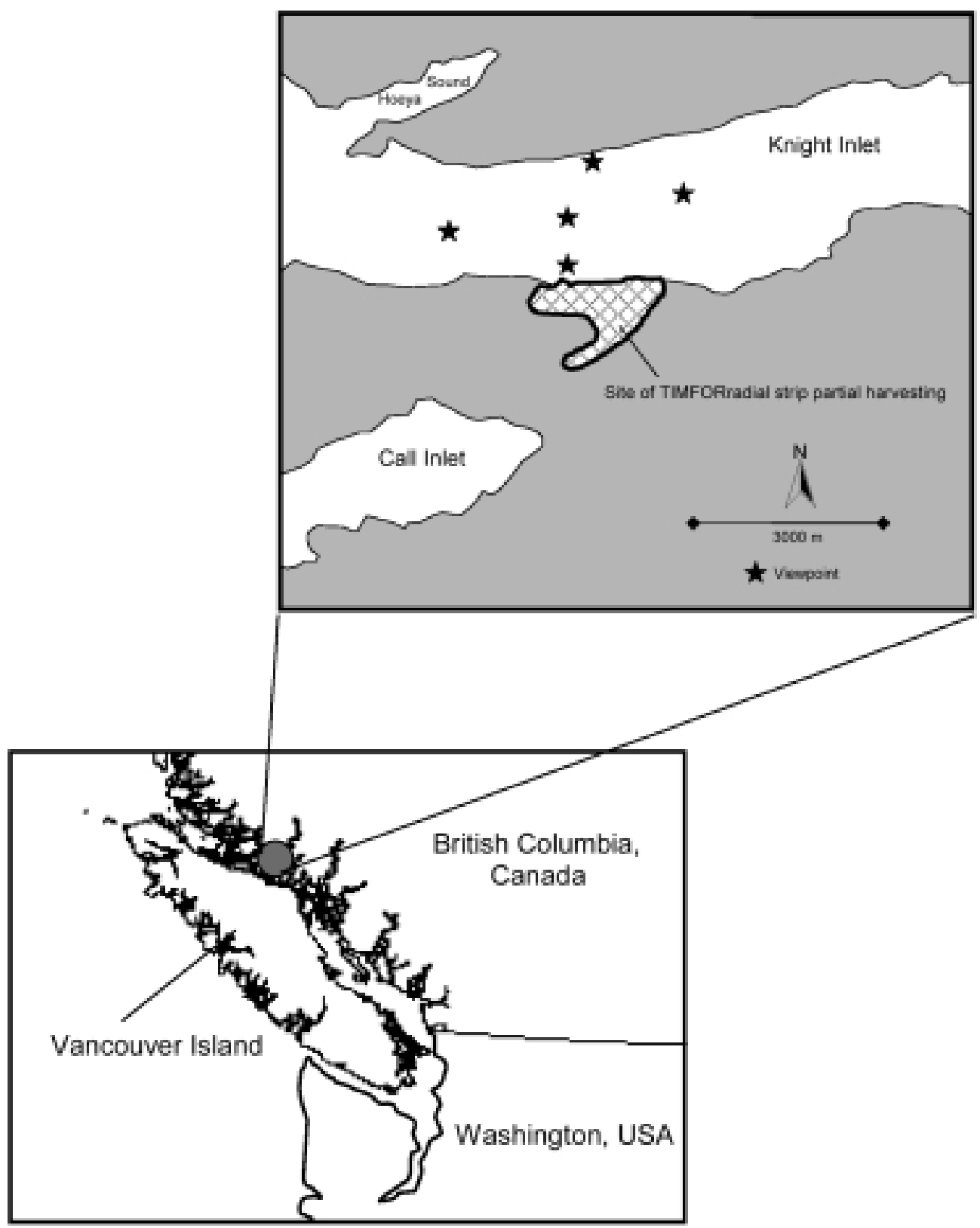

Fig. 1. Site of the Timfor Contracting Ltd. experimental radial-strip harvest area located along the north-facing slopes of Knight Inlet on coastal British Columbia. Stars indicate viewpoints (with associated identification number) used in visual impact assessments.

between blocks (Province of British Columbia 1996), resulting in harvest units spread over a landscape rather than concentrated in one localized area. With the partial cutting performed in this case, however, since $40 \%$ of the original stands were retained, adjacency requirements were not imposed and more concentrated operations were enabled.

The current silviculture prescription calls for a second and final entry in 35 years. If the plan is implemented as prescribed, most or all of the trees retained during the first pass will be removed in the second entry. Natural regeneration of harvested areas is proposed to reach visually effective greenup (i.e., the height of new trees is sufficient to be perceived as a growing forest rather than a clearcut area; BC Ministry of Forests
1994) by that time. In addition, blocks will be assessed for planting opportunities, and Douglas-fir will be planted if appropriate.

\section{Post-Harvest Visual Assessments}

We performed a post-harvest assessment of the visual quality of the harvest operations adapted from methods described in the current Visual Impact Assessment (VIA) guidelines (BC Ministry of Forests 2001). Briefly, this method uses viewpoints, selected by assessors, from which consistency with target visual quality objectives (VQOs) is assessed. A VQO is a resource management objective that reflects the desired level of visual quality based on the physical characteristics and social concern for the area. A typical pre-harvest VIA 


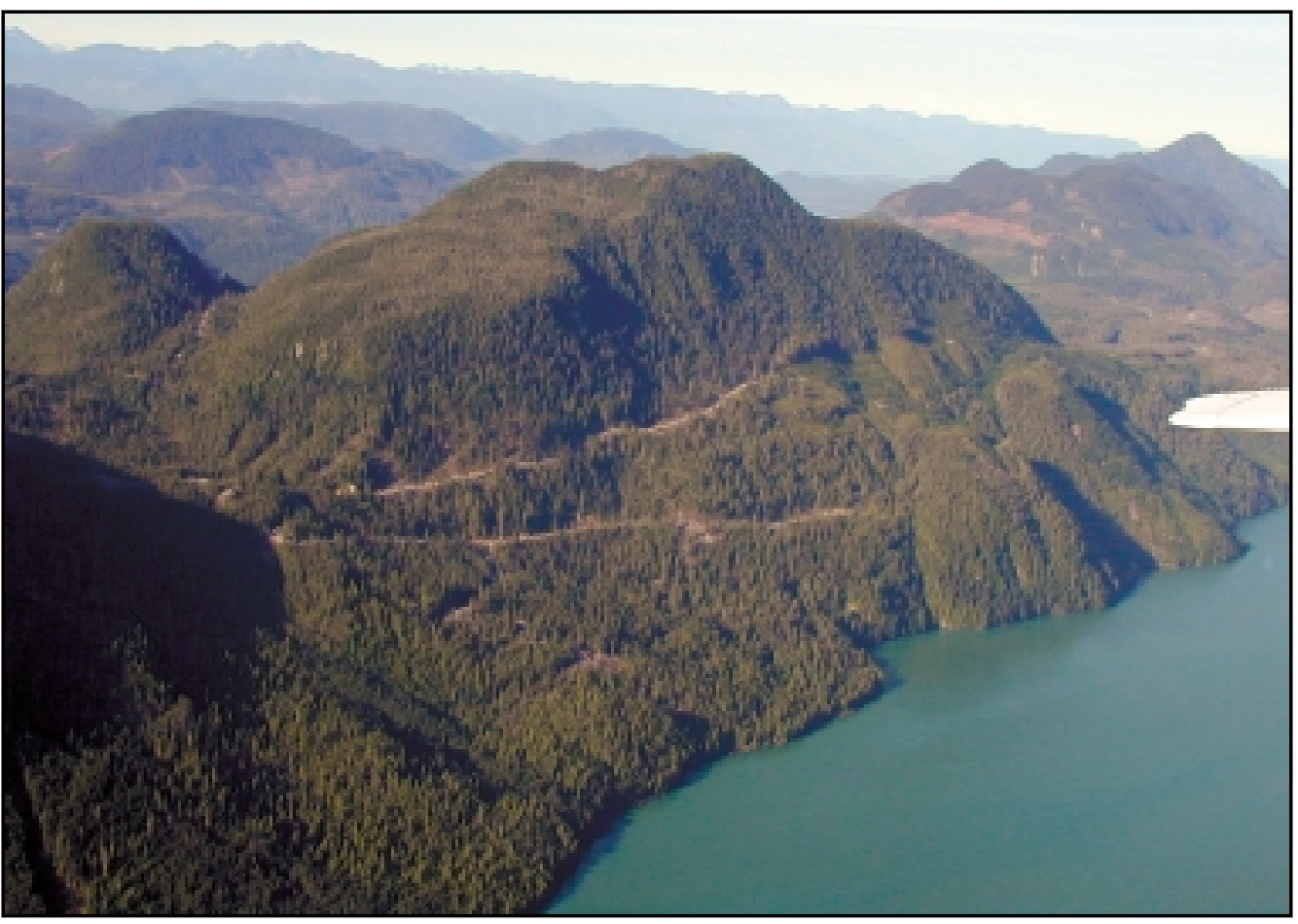

Fig. 2. Post-harvest aerial photo of Timfor Contracting Ltd. experimental radial-strip harvesting located along the north-facing slopes of Knight Inlet on coastal British Columbia.

includes a simulation, in perspective view, of the expected visual effects of proposed timber harvesting and road construction that will modify the scenic landscape (Sheppard 2000). The simulation is then used to assess whether or not the specific VQOs for that area would be achieved given a proposed harvesting plan. There are currently five levels of VQO identified by the BC Ministry of Forests (2001) through a visual landscape inventory process: (1) Preservation $=$ no visible activities; (2) Retention = activities are not visually evident; (3) Partial retention = activities are evident, but remain subordinate; (4) Modification = activities are visually dominant, but have characteristics that appear natural; and (5) Maximum Modification $=$ activities are dominant and out of scale, but appear natural in the background. Consistency with VQOs is typically assessed by professional landscape architects, landscape foresters, or recreation technicians trained in visual resource management. Fig. 1 illustrates the selected viewpoints used for pre-harvest simulations and the post-harvest VIA in this case. Viewpoints were originally selected (as part of the pre-harvest VIA process) to represent a broad range of viewing conditions and viewing angles from the water (Knight Inlet), as well as to represent anticipated worst-case viewing conditions (Fig. 1).

Prior to harvesting, the area had a recommended VQO of Partial Retention, requiring management activities to remain subordinate in the landscape. A consulting landscape forester (Fairhurst 1998 and 2000) had prepared visual simulations within World Construction Set, a visual simulation software package, and performed pre-harvest VIAs to ensure proposed harvesting would meet this VQO (Fig. 4 and 5). Typically, under provincial guidelines (BC Ministry of Forests 2001), these assessments are made using the professional judgement of one or more trained and experienced landscape foresters or other qualified landscape professionals familiar with the provincia VIA procedure.

The procedure used for the post-harvesting visual impact assessment, in this case, included the following steps consistent with provincial guidelines: (1) Evaluation of VQOs achieved in the field, conducted by the two authors with training and experience in applying VQOs (S. Sheppard, P. Picard), under grey sky summer conditions; (2) a second evaluation in the field by P. Picard, under sunny summer conditions; (3) review and evaluation of panoramic colour photography collected from both field trips, in comparison with pre-harvest colour photographs from the original VIA; and (4) additional evaluation of VQO achievement by the original landscape forester responsible for the pre-harvest assessment, in the field and using post-harvesting photography. The on-site assessments and photography were conducted from a boat on Knight Inlet, and were performed using the same viewpoints as those used in the pre-harvest VIA and simulations (Fig. 1), located with the aid of field mapping, onsite comparison with pre-harvest photographs, and global positioning system equipment. A more quantitative calculation of percent alteration of the landscape (i.e., the proportion of the visual landscape unit which is visibly modified by harvesting, seen in perspective; BC Ministry of Forests 2001) was not conducted because it does not take into account key factors such as shape and edge effects of modifications and is difficult to apply reliably in selection harvesting operations with subtle textural and colour patterns. The post-harvest assessments of the actual visual impact resulted in a consensus that two of the three harvest blocks met a partial retention VQO; and the third block met a more restrictive Retention VQO, whereby modifications would be barely noticeable to most observers.

A comparison of the simulations and the post-harvest photographs (Fig. 4 and 5) was also conducted. This involved comparisons 

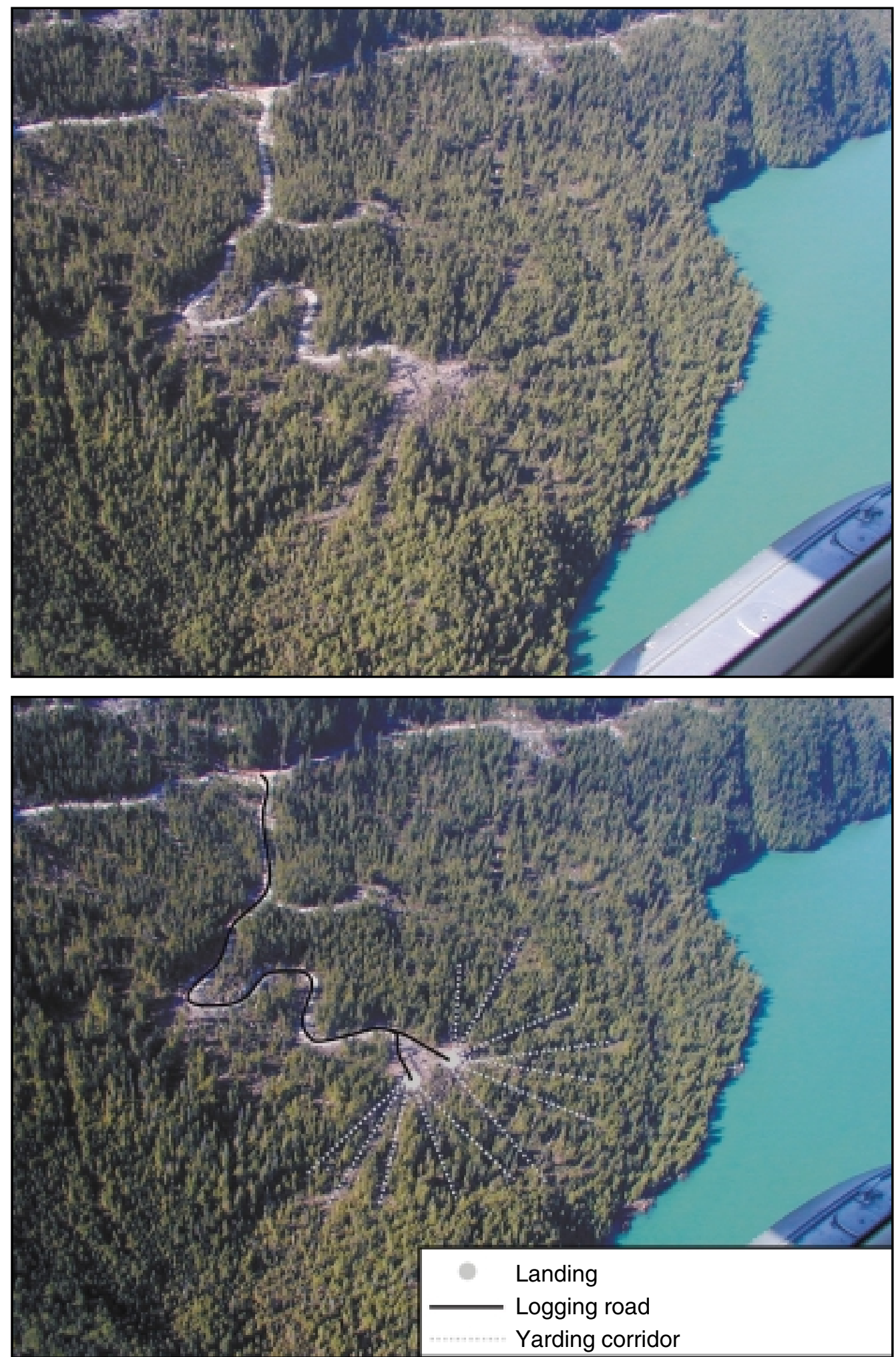

Fig. 3. Layout and design of the radial-strip selection methods used in an experimental selection harvest designed to meet visual quality requirements in southwest British Columbia, 1998-2000. Bottom photo is the top photo superimposed with road and block layout plans.

of the location, scale, and colour/texture contrasts shown in the simulations and corresponding panoramic photographs. The evaluation considered the accuracy of depiction of roads and associated disturbance or rock exposures, landings, radial strips, and adjoining vegetation textures. Accuracy of visual simulations was assessed qualitatively, in order to take into account differences in lighting, image resolution and format between simulations and photographs, and unavoidable minor discrepancies in view- 

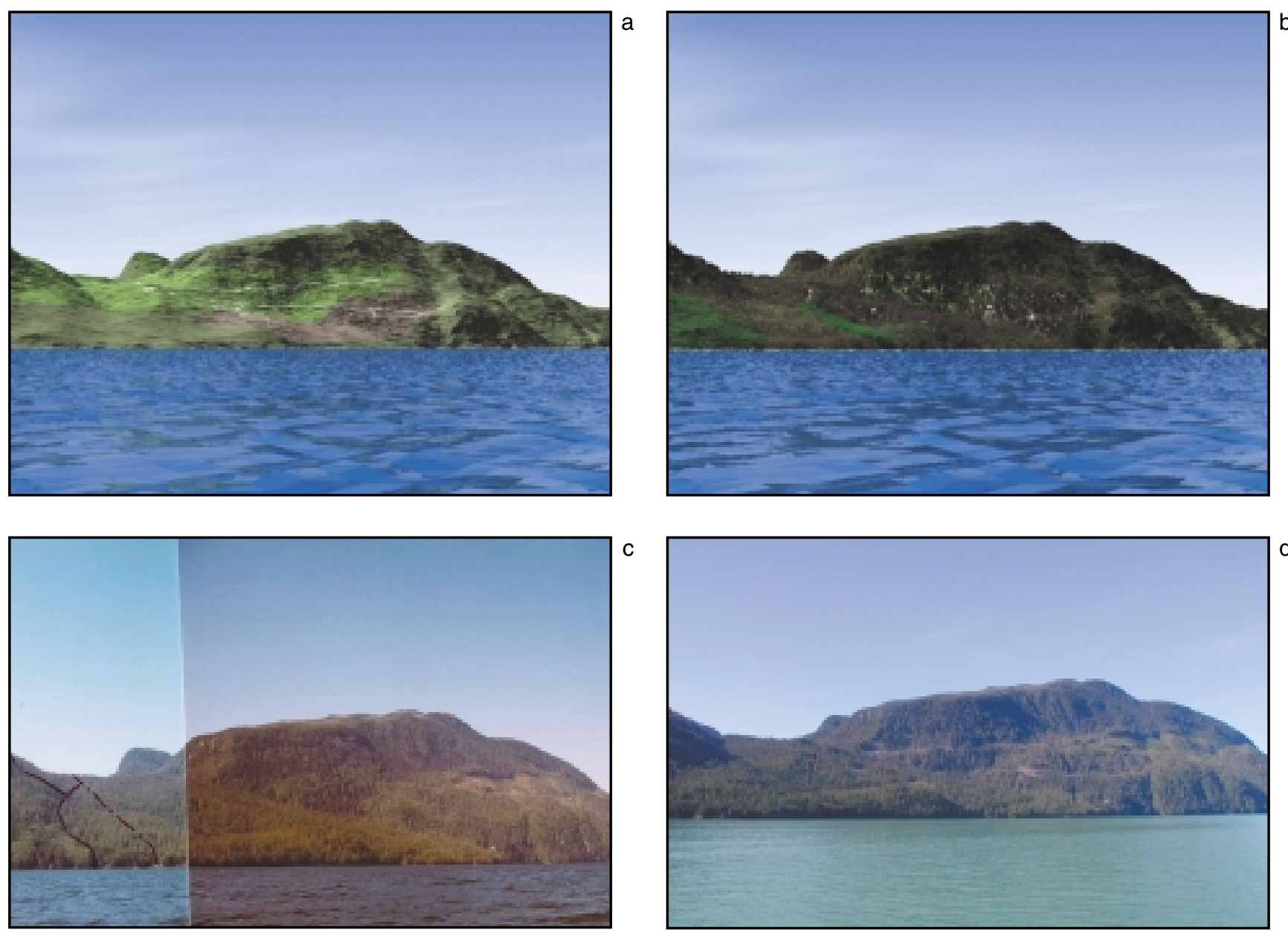

Fig. 4. Four images from viewpoint 3 representing: (a) simulation showing coloured landscape with planned roads but without vegetation; (b) simulation of planned roads, forest vegetation, and planned logging; (c) pre-harvest photograph; and (d) post-harvest photograph. Simulations were performed by Ken Fairhurst (Resource Design Inc.) using World Construction Set software.

point location on the water. The analysis showed that post-logging visual conditions were very similar to and overall slightly superior to that anticipated and represented in the simulations, with the exception of some of the roads (especially those on steep slopes) which had a greater negative visual impact than anticipated based on the simulations. This was due primarily to colour contrast and linearity of uphill cutbanks, exposed rock, and debris at the downhill sides of roads and landings, with some reduced screening near landings.

\section{Discussion}

While the concept of radiating strip harvesting is not new (US Forest Service 1974) we believe the operational application of this harvesting pattern specifically to meet rigorous and documented visual objectives at Knight Inlet is a first within BC. This post-harvest case study demonstrates the effectiveness of this technique in meeting restrictive VQOs in an area of high visual sensitivity while permitting substantial amounts of timber extraction. Given that the amount of available timber under a traditional clearcutting approach was effectively zero (i.e., traditional clearcutting was not an option), the volumes obtained by Timfor in this case greatly exceeded what would have been available under a more traditional approach. We sug- gest this illustrates that certain methods of partial cutting, where feasible, may virtually eliminate visual quality as a major constraint on forest management and timber extraction when visual designs are carefully implemented (Picard 2002; Picard and Sheppard 2002a, b).

We attribute the success of this harvest operation in minimizing the visual impacts of harvesting in such a visible and sensitive location to the following factors: (1) The radial pattern of linear clearings means that from any given viewpoint, it is not possible to see into more than a few of the cleared strips, since most cleared strips run across a viewer's line of sight and bare ground is screened by adjoining leave strips; (2) At no time does the observer see a regular series of parallel (and obviously manmade) geometric clearings; (3) The narrow width of the clearings maximises the amount of screening of bare ground by the adjacent leave-trees. Only when the line of sight is aligned closely with the linear axis of the clearing is bare ground visible; (4) The selective removal of trees between the clearings is carefully feathered (with more trees removed at the edges of the leave strip than in the centre of the leave strip), so as to avoid highly contrasting edges; (5) The retention of a full stand profile of age classes, given that the original stand was multi-storied, leaving numerous prominent old-growth trees and understory, which 

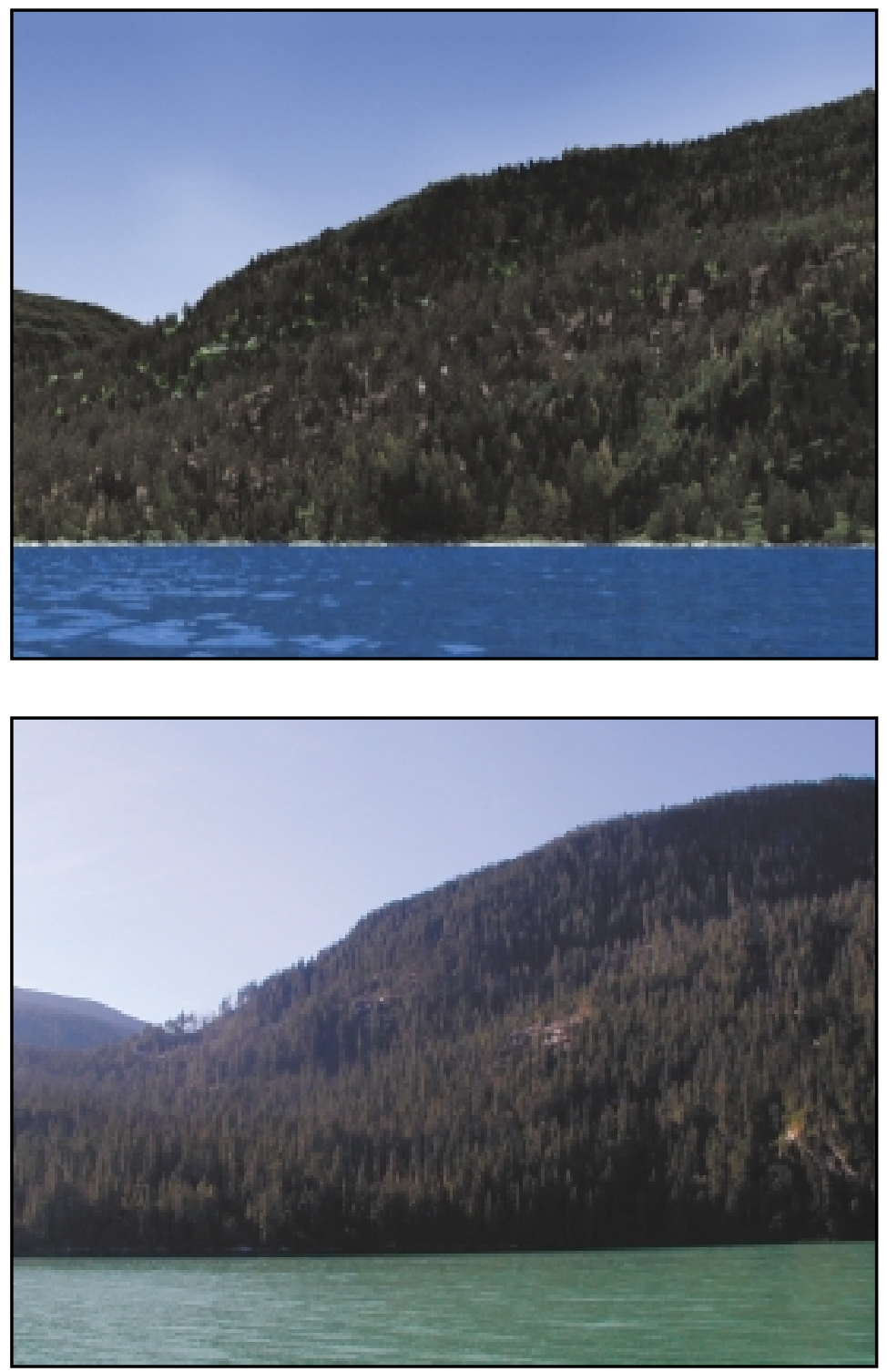

Fig. 5. Two images from viewpoint 5 representing close-up views of: (a) simulation of planned roads, forest vegetation, and planned logging; and (b) post-harvest photograph. Simulations were performed by Ken Fairhurst (Resource Design Inc.) using World Construction Set software.

reduced the amount of visible bare ground and associated visual contrast in relation to the adjacent uncut areas.

Despite this overall success, some of the roads on very steep slopes had more of a noticeable visual impact than anticipated in the simulations. It should be noted that it is currently very difficult to predict road construction appearance accurately in visual simulations due to unknown inaccuracies in terrain data. In reality, roads (including displaced granite boulders and blasted rock bluffs) and dried-out logging slash (which turned grey/white only a year after harvest) were the two most prominent visual cues that logging had occurred on these slopes. Therefore, visual quality could potentially be further improved if more careful visual design consideration is given to on-site road construction and logging slash. Specific measures for reducing the visual impact of roads include using narrower road rightof-way (road surface width $=4.9 \mathrm{~m}$ in this study) and leaving more screen trees immediately below the road. As well, visual quality could be improved by either reducing the amount of slash created or removing logging slash from prominent locations on-site.

Another concern is whether or not future passes will meet visual quality requirements, and this remains to be tested. This is especially of concern if all or most of the trees retained in the first pass are removed in the second pass as planned. Future considerations of this nature are critical and we suggest that, depending on the location of second-pass landings and yarding corridors, simply meeting visually effective green-up height requirements (BC Ministry of Forests 2001) at the time of the second pass may not be enough to meet visual quality requirements. Rather, more time between passes (to allow more regrowth of harvested areas), or more retention of original trees in key areas, may be required to ensure that second- 
pass visual quality requirements are met, as suggested by Picard (2002).

Furthermore, the feasibility of partial cutting in British Columbiaís coastal old-growth is not well understood and achieving harvesting productivities and costs of these activities is paramount to its future success. A detailed account of costs and operational feasibility associated with the first two blocks harvested in this study is provided by Boswell (2001). Briefly, and for comparison purposes with future studies, we present several productivity and cost summaries associated with the radial-strip harvesting performed in this study (see Boswell 2001 for details): engineering productivity was 4.7 and 3.4 person days/ha for blocks 1 and 2, respectively; engineering labour costs were $\$ C A N 3.77 / \mathrm{m}^{3}$ and $2.22 / \mathrm{m}^{3}$ for blocks 1 and 2 , respectively; falling productivity averaged $135 \mathrm{~m}^{3} /$ person day and falling costs were $\$ C A N 3.46 / \mathrm{m}^{3}$; cable yarding productivity averaged $108 \mathrm{~m}^{3} / 8-\mathrm{hr}$ shift and cable yarding costs were $\$ C A N 30.42 / \mathrm{m}^{3}$.

Timfor reported (E. Preus, personal communication) that these figures represent increases of approximately $25 \%$ to $40 \%$ in falling costs, $45 \%$ in yarding costs, and $50 \%$ in planning (layout) costs, when compared with a traditional clearcutting operation. These costs are understood to be below the level of helicopter-logging costs in similar conditions (E. Preus, personal communication). However, the stumpage appraisal system (the cost per unit of wood charged by the province to a licensee) in this case allowed a decrease of \$16 to \$21 (\$CAN) per $\mathrm{m}^{3}$ to offset all extra falling, yarding, and planning costs. Therefore, while additional falling, yarding, and planning were required by TIMFOR to harvest in this case, net costs were approximately equal to that which would have been incurred under a traditional clearcutting operation. As well, Boswell (2001) clearly indicated improvements in productivity and lower costs with the second block relative to the first, suggesting that experience in these methods should increase productivity and efficiency, leading to lower costs in the future. A rigorous analysis of these costs within the stumpage pricing system is beyond the scope of this paper. It is unknown what stumpage appraisal allowances would be provided to other licensees in other situations. In our case, the allowances offset the extra costs associated with this operation. Stumpage appraisal allowances are therefore a major consideration for other operators elsewhere.

It appears that a major contributing factor to the success of this experimental harvesting operation was the attitude, experience, and training of fallers. This is consistent with Jones (1995) and Picard (2002, and references therein), who reported that some of the most important factors in the success of a visually sensitive harvest operation is the attitude of the loggers, their involvement in the planning stages, whether they are willing to do a high quality job, and whether they believe in managing the forests for their aesthetic values. To this end, we suggest that managers wishing to replicate harvest operations of this nature make selection and training of fallers a priority.

Despite the success of this operation from a visual resource management standpoint, other issues requiring further examination at this or other sites pioneering new partial cutting approaches include, among others, worker safety and long-term impacts on biodiversity, hydrology, slope stability, windthrow, forest health, and forest productivity. Identification of real problems related to these issues could reduce expected visual quality and timber supply gains associated with harvesting tech- niques of this kind. For example, in this case, large distances between corridors in the locations farthest from the landings resulted in fewer trees removed in these areas. As well, sidehill yarding required by the radial corridors used in this case can damage the carriage or residual trees when working on steep ground. These and other issues related to this kind of operation require further examination.

Finally, as a direct consequence of the experimental harvest operation described here and as a tribute to its overall success, Timfor recently acquired Forest Stewardship Council (FSC) certification for these blocks - among the first FSC certifications in Canada (SmartwoodBC 1999). To date, Timfor has received only positive comments pertaining to the visual appearance of their logging operation in Knight Inlet. It therefore appears to set a precedent worthy of further application and testing in visually sensitive areas elsewhere.

\section{Acknowledgements}

We are grateful to Ken Fairhurst for his participation and information related to pre-harvest VIAs. We thank Esmond Preus of Timfor Contracting Ltd. for providing information on harvesting specifications, and three anonymous reviewers for reviews of a previous draft. Graduate student support was provided to P. Picard by the Faculty of Forestry, University of British Columbia, and the Arrow Innovative Forest Practices Agreement. Additional funding for the publication of this work was provided by the British Columbia Forest Innovation Investment program.

\section{References}

BC Ministry of Forests. 1994. A first look at visually effective greenup in British Columbia: a public perception study. British Columbia Ministry of Forests, Technical Report 1994:1, Victoria, BC.

BC Ministry of Forests. 1995. Biodiversity guidebook. BC Forest Practices Code Guidebook, British Columbia Ministry of Forests, Victoria, BC.

BC Ministry of Forests. 1996. Clearcutting and visual quality: a public perception study. British Columbia Ministry of Forests, Victoria, BC BC Ministry of Forests. 2001. Visual impact assessment guidebook. 2nd edition. British Columbia Ministry of Forests, Forest Practices Branch, BC.

Boswell, B. 2001. Partial cutting with a cable yarding system in coastal British Columbia. Forest Engineering Research Institute of Canada, Vancouver, BC. Advantage 2: 44.

Fairhurst, K. 1998. Visual impact assessment for block K-2 FLA53812. Unpublished report submitted to Timfor Contracting Ltd., Campbell River, BC.

Fairhurst, K. 2000. Visual impact assessment for block K-3 FLA53812. Unpublished report submitted to Timfor Contracting Ltd., Campbell River, BC.

Green, R.N. and K. Klinka. 1994. A field guide to site identification and interpretation for the Vancouver forest region. British Columbia Ministry of Forests, Victoria, BC.

Johnson, W.L. 1998. Skyline innovation exceeding expectations. Truck Logger 21(4): 6-12.

Jones, G.T. 1995. The careful timber harvest: a guide to logging aesthetics. Journal of Forestry 93: 12-15.

Pâquet, J. and L. Bélanger. 1997. Public acceptability thresholds of clearcutting to maintain visual quality of boreal balsam fir landscapes. Forest Science 43: 46-55.

Picard, P. 2002. Do visual quality objectives necessarily constrain timber harvest levels: exploring the potential of partial cutting. MSc thesis, Faculty of Forestry, University of British Columbia, Vancouver, BC. 
Picard, P. and S.R.J. Sheppard. 2002a. The effects of visual resource management on timber availability: a review of case studies and policy. British Columbia Journal of Ecosystems and Management 1: 73-84.

Picard, P. and S.R.J. Sheppard. 2002b. Partial cutting in the frontcountry: a win-win solution for short-term timber availability and aesthetics? British Columbia Journal of Ecosystems and Management 1: 85-102.

Province of British Columbia. 1996. Forest practices code of British Columbia act. Revised statues of British Columbia, chapter 159. Victoria, BC.

Robson, M., A. Hawley and D. Robinson. 2000. Comparing the social values of forest-dependent, provincial and national publics for socially sustainable forest management. The Forestry Chronicle 76: 615-622.

Sheppard, S.R.J. 2000. Visualization as a decision-support tool in managing forest ecosystems. Compiler 16(1): 25-40.
Sheppard, S.R.J. 2001. Beyond visual resource management: emerging theories of an ecological aesthetic and visible stewardship. In S.R.J. Sheppard and H.W. Harshaw (eds.). Forests and landscapes: linking ecology, sustainability and aesthetics. pp. 149-172. CABI Publishing, New York, New York.

Siddall, M. 2000. Variable retention logging presents new challenges for yarding operations. Business Logger, March issue.

Smartwood BC. 1999. Northwest Natural Resource Group/Smartwood BC Certification assessment report for Timfor Contractors Ltd. Final confidential report, 10 December, 1999. Smartwood, Richmond, Vermont.

Stathers, R.J., T.P. Rollerson and S.J. Mitchell. 1994. Windthrow handbook for British Columbia forests. Working Paper 9401, British Columbia Ministry of Forests, Victoria, BC.

US Forest Service. 1974. National landscape management. USDA Agricultural Handbook No. 462, Washington, DC. 